\title{
Electrospinning of nanofibers from non-polymeric systems: polymer-free nanofibers from cyclodextrin derivatives
}

\author{
Asli Celebioglu and Tamer Uyar* \\ Received 21st September 2011, Accepted 3rd November 2011 \\ DOI: 10.1039/c1nr11364j
}

\begin{abstract}
High molecular weight polymers and high polymer concentrations are desirable for the electrospinning of nanofibers since polymer chain entanglements and overlapping are important for uniform fiber formation. Hence, the electrospinning of nanofibers from non-polymeric systems such as cyclodextrins (CDs) is quite a challenge since CDs are cyclic oligosaccharides. Nevertheless, in this study, we have successfully achieved the electrospinning of nanofibers from chemically modified CDs without using a carrier polymer matrix. Polymer-free nanofibers were electrospun from three different $C D$ derivatives, hydroxypropyl- $\beta$-cyclodextrin $(\mathrm{HP} \beta \mathrm{CD})$, hydroxypropyl- $\gamma$-cyclodextrin $(\mathrm{HP} \gamma \mathrm{CD})$ and methyl- $\beta$-cyclodextrin $(\mathrm{M} \beta \mathrm{CD}$ ) in three different solvent systems, water, dimethylformamide (DMF) and dimethylacetamide (DMAc). We observed that the electrospinning of these CDs is quite similar to polymeric systems in which the solvent type, the solution concentration and the solution conductivity are some of the key factors for obtaining uniform nanofibers. Dynamic light scattering (DLS) measurements indicated that the presence of considerable $\mathrm{CD}$ aggregates and the very high solution viscosity were playing a key role for attaining nanofibers from $\mathrm{CD}$ derivatives without the use of any polymeric carrier. The electrospinning of $\mathrm{CD}$ solutions containing urea yielded no fibers but only beads or splashes since urea caused a notable destruction of the self-associated CD aggregates in their concentrated solutions. The structural, thermal and mechanical characteristics of the CD nanofibers were also investigated. Although the $\mathrm{CD}$ derivatives are amorphous small molecules, interestingly, we observed that these electrospun CD nanofibers/nanowebs have shown some mechanical integrity by which they can be easily handled and folded as a free standing material.
\end{abstract}

\section{Introduction}

Electrospinning has become the most attractive nanofiber production technique in the past decade due to its cost-effectiveness and versatility. This technique facilitates the production of ultrafine fibers from a variety of materials such as polymers, polymer blends, sol-gels, composites, etc. ${ }^{1-3}$ In the electrospinning technique, a continuous filament is electrospun from polymer solutions or polymer melts under a very high electrical field, which resulted in ultrafine fibers ranging from tens of nanometres to a few microns in diameter. ${ }^{1}$ The morphology and the diameter of the electrospun nanofibers depend on (i) electrospinning process parameters such as applied voltage, tip-tocollector distance, flow rate of the polymer solution and nozzle diameter; (ii) polymer type, molecular weight, type of solvent, concentration, surface tension and conductivity of the polymer solution, and fluid elasticity and (iii) environmental conditions such as humidity and temperature. ${ }^{1,4-12}$ Electrospun nanofibers/ nanowebs have numerous remarkable characteristics such as

UNAM-Institute of Materials Science \& Nanotechnology, Bilkent University,Ankara,06800,Turkey.E-mail:tamer@unam.bilkent.edu.tr very high surface-to-volume ratio having highly porous structures in the nanoscale and they show distinctive physical and mechanical properties. Unique properties and the multi-functional nature of these electrospun nanofibers make them applicable in various fields including biotechnology, membranes/ filters, textiles, sensors, electronics, energy, etc. ${ }^{1-3,13-18}$

Cyclodextrins (CDs) are natural and nontoxic cyclic oligosaccharides which are produced from starch by means of enzymatic conversion. CDs have a truncated cone-shaped molecular structure which can form intriguing supramolecular structures by forming non-covalent host-guest inclusion complexes with a variety of molecules. ${ }^{19,20} \mathrm{CDs}$ are particularly applicable in many areas including pharmaceuticals, functional foods, filters, cosmetics, textiles as well as advanced functional systems such as smart materials, sustained/controlled delivery systems, sensors, molecular switches and devices, etc. ${ }^{19-23}$ The most common cyclodextrins are named $\alpha-C D, \beta-C D$ and $\gamma-C D$ having six, seven or eight glucopyranose units in the cyclic structure, respectively (Fig. 1). Native cyclodextrins ( $\alpha-\mathrm{CD}, \beta-\mathrm{CD}$ and $\gamma$-CD) are soluble in water, yet, their solubility is rather limited due to the presence of intramolecular hydrogen bonding within the $\mathrm{CD}$ molecule which prevents the formation of hydrogen 

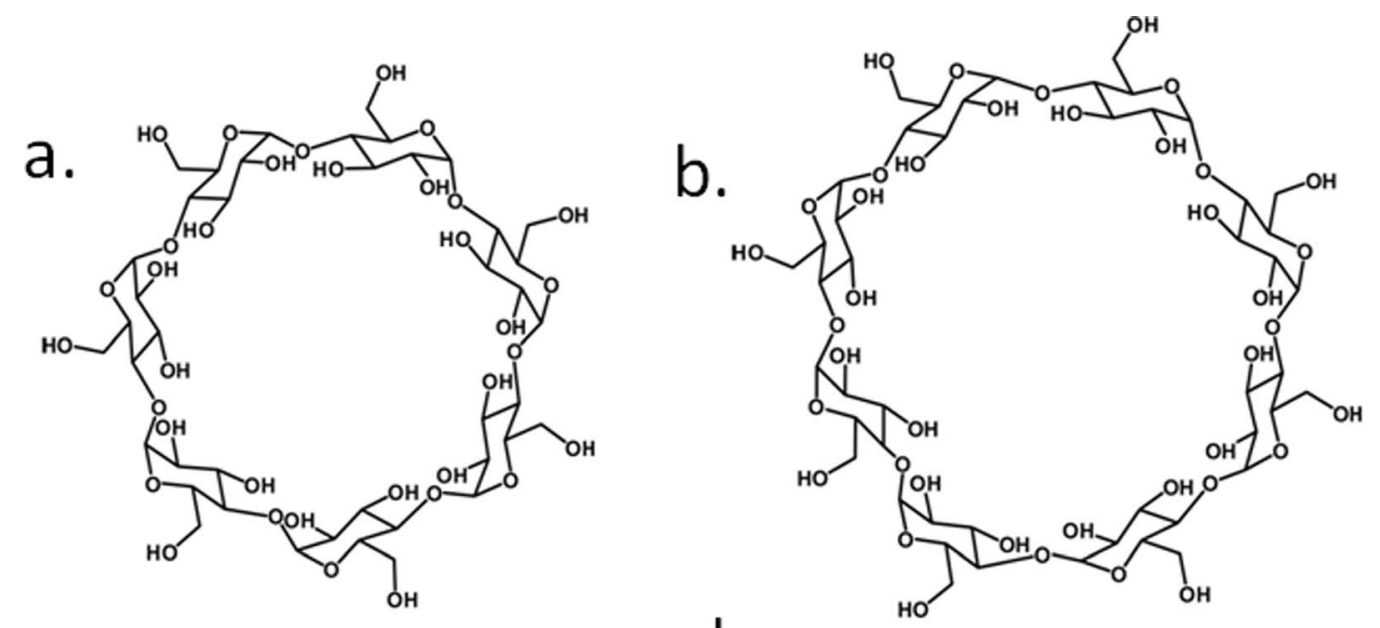

C.
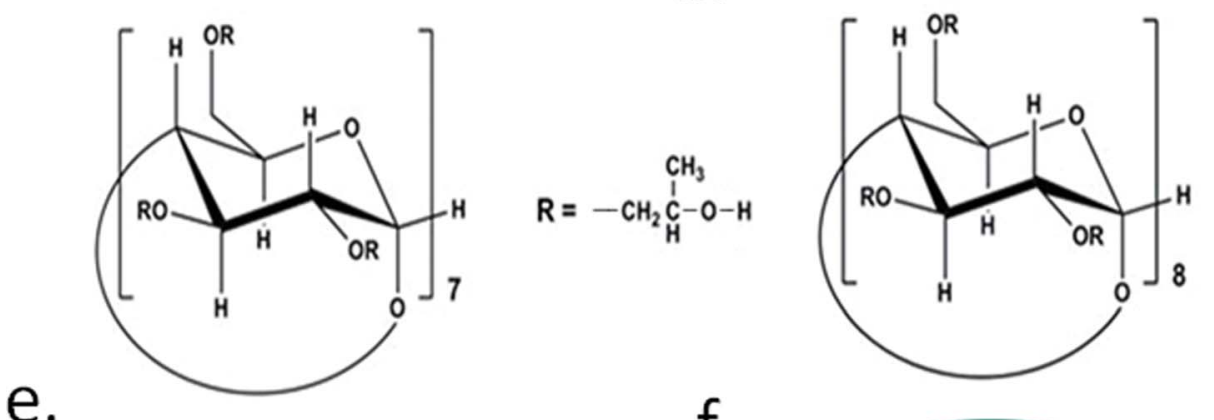<smiles>[R]#CCC(O)O</smiles>
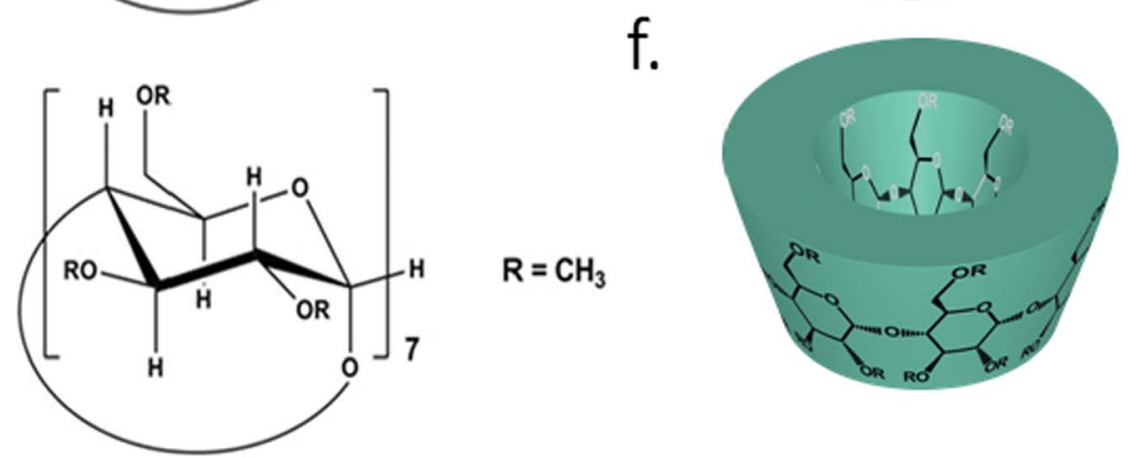

Fig. 1 Chemical structure of (a) $\beta$-cyclodextrin ( $\beta$-CD), (b) $\gamma$-cyclodextrin $(\gamma$-CD), (c) hydroxypropyl- $\beta$-cyclodextrin (HP $\beta C D)$, (d) hydroxypropyl- $\gamma$ cyclodextrin ( $\mathrm{HP} \gamma \mathrm{CD}$ ) and (e) methyl- $\beta$-cyclodextrin $(\mathrm{M} \beta \mathrm{CD})$; (f) schematic representation of a truncated cone-shaped molecular structure of cyclodextrin.

bonds with surrounding water molecules. ${ }^{24,25}$ However, the chemical modification of CDs (e.g. methyl-CD and hydroxypropyl-CD) obtained by random substitution of the hydroxyl groups of CD with methyl or hydroxypropyl groups resulted in amorphous CD solids having much higher aqueous solubility compared to native CDs. ${ }^{24}$

In general, electrospinning of nanofibers involves high molecular weight polymers and high solution concentrations since entanglements and overlapping between the polymer chains play an important role for the continuous stretching of electrified jet for uniform fiber formation;, 1,7,8,26,27 otherwise, for small molecules, electrospraying occurs which yields only beads instead of fibers. ${ }^{28}$ Hence, the electrospinning of nanofibers from non-polymeric systems is quite a challenge. Yet, recently Long et al. showed that micron size fibers of low molar mass gemini surfactant $^{29}$ and phospholipid ${ }^{30}$ can be electrospun since these molecules can form cylindrical micelles in their concentrated solutions which can be overlapped and entangled in a fashion similar to polymers. CDs are cyclic oligosaccharides which are capable of self-assembly and form aggregates via intermolecular hydrogen bonding in their concentrated solutions. ${ }^{25,31,32}$ Such aggregates present in the CD solutions can be effective for the electrospinning of CDs into nanofibers. In fact, very recently, we have achieved the electrospinning of polymer-free nanofibers from methyl- $\beta$-cyclodextrin $(\mathrm{M} \beta \mathrm{CD})^{33}$ and an inclusion complex of hydroxypropyl- $\beta$-cyclodextrin (HP $\beta C D$ ) with triclosan. ${ }^{34}$ Following our very recent studies, ${ }^{33,34}$ here we have extensively investigated the electrospinning of nanofibers from three different chemically modified CDs (HP $\beta C D, H P \gamma C D$ and $\mathrm{M} \beta \mathrm{CD}$ ) in three different solvent systems (water, DMF and DMAc) without using any carrier polymer matrix. We observed that the morphology and the diameter of the resulting 
electrospun fibers significantly vary with the type of CDs as well as the type of solvent systems used. We have also investigated the structural, thermal and mechanical characteristics of these electrospun CD nanofibers/nanowebs.

\section{Results and discussion}

In this study, we have carried out electrospinning of nanofibers from three different cyclodextrin derivatives, HP $\beta C D, H P \gamma C D$ and $M \beta C D$ in three different solvent systems: water, DMF and DMAc without using a polymeric carrier matrix. In electrospinning of polymers, the morphology of the electrospun nanofibers is affected by the polymer solution properties such as polymer type, solvent type, solution concentration and/or viscosity, solution conductivity, etc. ${ }^{\mathbf{1 4 - 1 2}}$ Here, we have investigated the effect of solvent type, concentration/viscosity and solution conductivity on the final morphology of electrospun nanofibers obtained from $\mathrm{HP} \beta C \mathrm{C}, \mathrm{HP} \gamma \mathrm{CD}$ and $\mathrm{M} \beta \mathrm{CD}$. Interestingly, we have observed that these CDs behave very similar to polymeric systems during the electrospinning process where the solvent type, solution viscosity and conductivity played a major role in the formation of bead-free uniform CD nanofibers.

\section{Electrospinning of hydroxypropyl- $\beta$-cyclodextrin (HPßCD) nanofibers}

The electrospun HP $\beta C D$ nanofibers were produced from water, DMF and DMAc solvent systems. The characteristics of HP $\beta C D$ solutions and the morphological properties of the resulting electrospun nanofibers are summarized in Table 1. For each solvent type, the initial HPßCD concentration was $100 \%$ $(\mathrm{w} / \mathrm{v})$ and increased up to the optimal concentration that nanofibers without beaded structure were produced. Bead-free HP $\beta C D$ nanofibers were obtained at $160 \%$ (w/v) for water (Fig. 2d) and at 120\% (w/v) for DMF (Fig. 2f) and DMAc (Fig. 2h). HPBCD nanofibers having fiber diameter in the range of 250-1780 nm $($ AFD $=745 \pm 370 \mathrm{~nm}), 400-1800 \mathrm{~nm}(\mathrm{AFD}=$ $1125 \pm 360 \mathrm{~nm})$ and $310-1860 \mathrm{~nm}($ AFD $=1360 \pm 295 \mathrm{~nm})$ were obtained from water, DMF and DMAc solvent systems, respectively (Table 1$)$.

The dynamic light scattering (DLS) and viscosity measurements were performed for concentrated HP $\beta C D$ solutions in order to understand the electrospinnability of HP $\beta C D$ by itself.
Substantial viscosity increase was observed as the concentration of the HP $\beta C D$ increased from $100 \%$ to $160 \%(w / v)$ in water, and from $100 \%$ to $120 \%(\mathrm{w} / \mathrm{v})$ in DMF and DMAc (Table 1$)$. The DLS measurements revealed the presence of self-aggregated HP $\beta C D$ molecules in their concentrated solutions (Fig. 3 and Table 1); in addition, it is evident that the sizes of the HP $\beta C D$ aggregates were increased and the particle size distribution became broader as the concentration of the HPBCD solution increased from $100 \%$ to $160 \%$ (w/v) in water. Similar trends were observed for DMF and DMAc solvent systems, that is, larger HP $\beta C D$ aggregates were formed as the concentration of the HP $\beta C D$ solution increased from $100 \%$ to $120 \%$ (w/v). Moreover, the size of the HPBCD aggregates was larger in DMF when compared to water. In the case of the DMAc solvent system, $\mathrm{HP} \beta C D$ aggregates were significantly bigger than the ones formed in water and DMF. Hence, the viscosity of the same HP $\beta C D$ concentrations $(100 \%$ and $120 \%(w / v))$ was highest in DMAc and lowest in water because of the differences in aggregate sizes. The DLS and viscosity data are in good agreement with each other and higher solution viscosity is owing to the higher amount of HP $\beta C D$ aggregates and their growing sizes as the concentration of the HP $\beta C D$ increased in water, DMF and DMAc solution systems.

At lower HP $\beta C D$ concentration $(100 \%$, w/v) in water, micronand nano-sized non-uniform beads were obtained (Fig. 2a). This is due to the presence of insufficient amount of HP $\beta C D$ aggregates at low concentration which resulted in destabilization of the electrified jet during the electrospinning and therefore yielded beads instead of continuous fibers. This behavior is typically observed for the electrospinning of polymer solutions having low concentration. When the concentration of the polymer solution is not at the optimal level, electrospraying occurs which yields only beads due to the lack of sufficient polymer chain entanglements and overlapping. ${ }^{1,8}$ Likewise, HP $\beta C D$ molecules at $100 \%$ (w/v) could not form sufficient aggregates to stabilize the electrospun jet for the formation of continuous fibers. When a $120 \%$ (w/v) aqueous HPßCD solution was electrospun, very fine fibers along with a substantial amount of beads were obtained (Fig. 2b). In the case of the $140 \%(w / v)$ concentration, the aqueous HP $\beta C D$ solution almost reached satisfactory viscosity value and aggregation size, so nanofibers along with some elongated beaded structures were obtained (Fig. 2c). Apparently, the transition from beaded structure to bead-free nanofibers was

Table 1 The characteristics of HP $\beta C D$ solutions, fiber morphology, average fiber diameter and fiber diameter range of the electrospun HP $\beta C D$ fibers. DLS measurements of HP $\beta C D$ solutions at $25^{\circ} \mathrm{C}$ summarizing the average diameter (nm) and polydispersity index (PDI) of HP $\beta C D$ aggregates

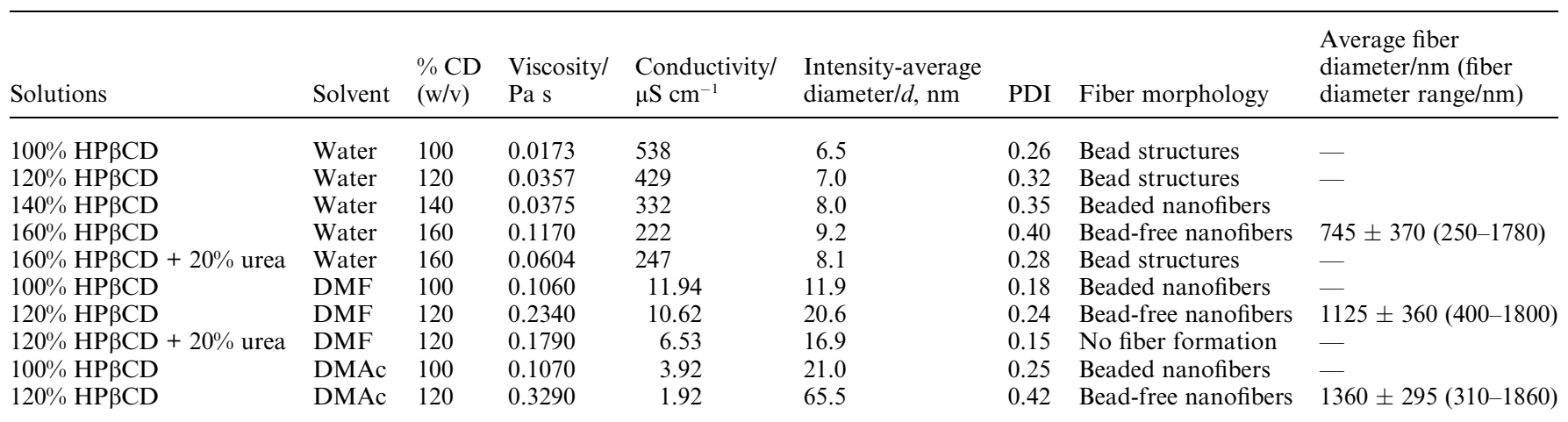



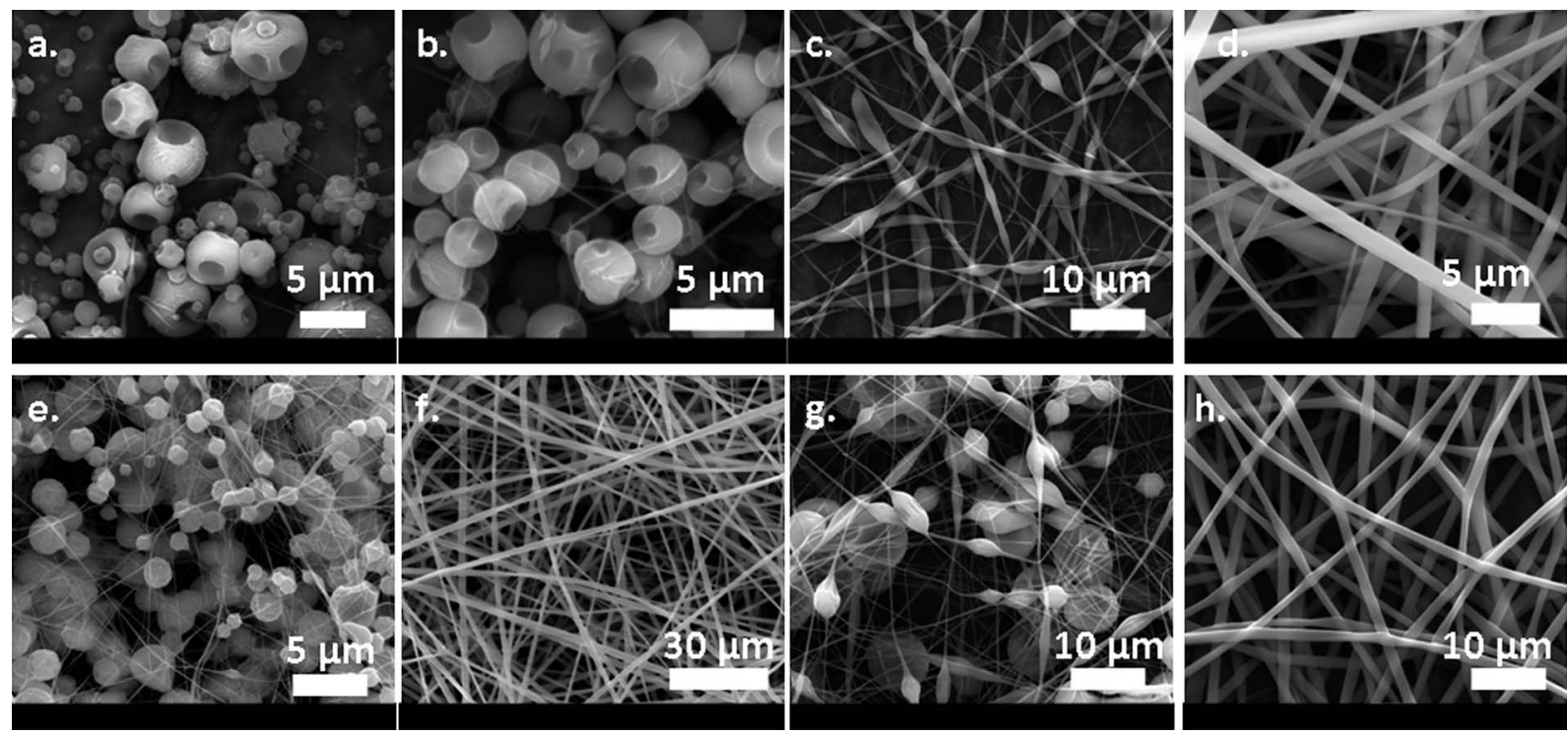

Fig. 2 The representative SEM images of the electrospun HP $\beta C D$ nanofibers obtained from water, DMF and DMAc solutions having different

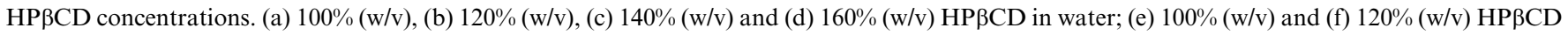
in DMF; and (g) 100\% (w/v) and (h) $120 \%$ (w/v) HPßCD in DMAc.

observed when a $160 \%(w / v)$ HPßCD aqueous solution was electrospun. At this concentration, bead-free HP $\beta C D$ nanofibers were produced with fiber diameters in the range of $250-1780 \mathrm{~nm}$ having an average fiber diameter of $745 \pm 370 \mathrm{~nm}$ (Fig. 2d). In the electrospinning of polymeric systems, bead-free fibers are usually obtained as the concentration of the polymer solution is increased $^{1,7-9}$ since polymer solutions with higher concentration have more chain entanglements which are very crucial to maintain the continuity of the jet during the electrospinning process. Here, we observed a very similar behavior for the electrospinning of HP $\beta C D$ nanofibers from its aqueous solution. The DLS measurements indicate that at higher concentrations, HP $\beta C D$ molecules form a considerable amount of aggregates which resulted in full stretching of the electrified solution jet and therefore yielded bead-free nanofibers.

HP $\beta C D$ nanofibers were also electrospun from its DMF solution. The beaded HP $\beta C D$ nanofibers were obtained at $100 \%$ (w/v) HP $\beta C D$ concentration in DMF (Fig. 2e). When a $120 \%$ (w/v) HP $\beta C D$ solution was electrospun, the bead-free nanofibers in the range of 400-1800 $\mathrm{nm}$ having an average fiber diameter of $1125 \pm 360 \mathrm{~nm}$ were produced (Fig. 2f). In DMF, the bead-free HP $\beta C D$ nanofibers were attained at much lower concentration but at higher fiber diameter when compared to the water system. The reason can be attributed to the larger aggregate size, higher viscosity and lower conductivity of the HP $\beta C D$ solution in DMF (Table 1) which yielded thicker fibers owing to less stretching of the jet during the electrospinning. At $120 \%(\mathrm{w} / \mathrm{v}) \mathrm{HP} \beta \mathrm{CD}$ in DMF, the aggregate size and viscosity were $20.6 \mathrm{~nm}$ and $0.234 \mathrm{~Pa}$ $\mathrm{s}$, respectively, whereas the aggregate size and viscosity were 9.2 $\mathrm{nm}$ and $0.117 \mathrm{~Pa} \mathrm{~s}$ for the $160 \%$ (w/v) $\mathrm{HP} \beta C D$ in water, respectively. In addition, the conductivity of the HP $\beta C D$ solution in DMF $\left(10.62 \mu \mathrm{S} \mathrm{cm}^{-1}\right)$ was much less than in its water solution $\left(222 \mu \mathrm{S} \mathrm{cm}{ }^{-1}\right)$. This behavior of $\mathrm{HP} \beta C D$ solution is very typical for the electrospinning of polymeric systems in which solutions having high viscosity and low conductivity yield thicker fibers because of the decreased stretching of the jet. ${ }^{1,9}$

The bead-free fibers were also obtained from the electrospinning of $\mathrm{HP} \beta C D$ in DMAc solution. The results were very
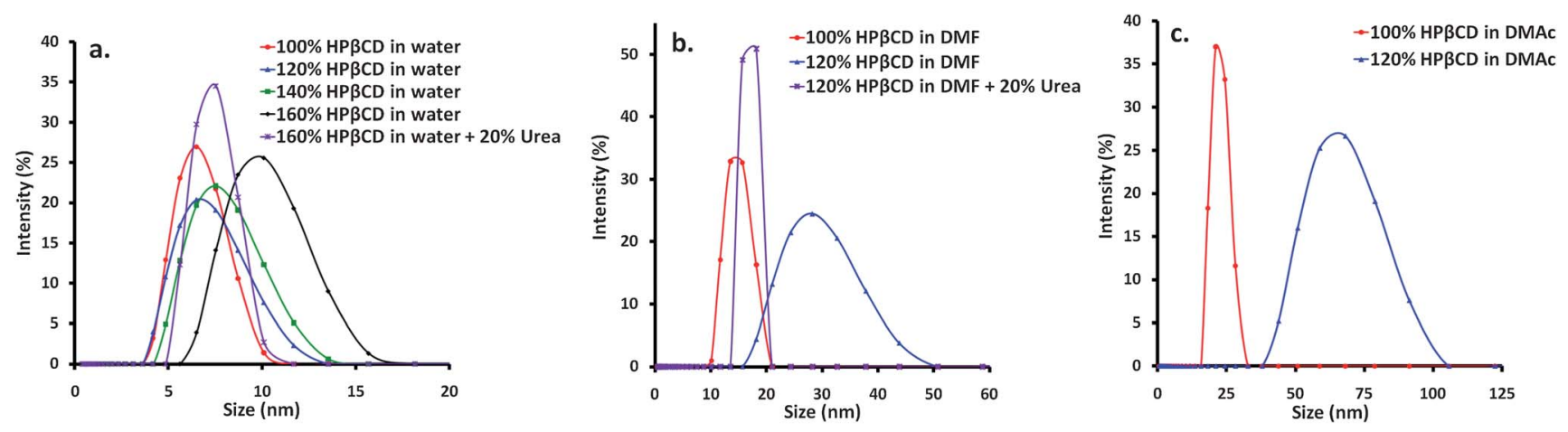

Fig. 3 Size distribution of HP $\beta C D$ aggregates for (a) 100\%, 120\%, 140\%, 160\% (w/v) HP $\beta C D$ and 160\% (w/v) HP $\beta C D$ containing 20\% (w/w) urea in water; (b) $100 \%, 120 \%$ (w/v) HP $\beta$ CD and $120 \%$ (w/v) HP $\beta C D$ containing $20 \%$ (w/w) urea in DMF; and (c) $100 \%$ and $120 \%$ (w/v) HP $\beta C D$ in DMAc. 
similar to the DMF solvent system, that is, at $100 \%(\mathrm{w} / \mathrm{v})$ HP $\beta C D$ in DMAc, beaded fibers were obtained (Fig. 2g), but bead formation was less and more fiber structures were present when compared to $100 \%$ (w/v) HPßCD in DMF (Fig. 2e). Beadfree $\mathrm{HP} \beta C D$ fibers were produced in the diameter range of 310 $1860 \mathrm{~nm}$ with the average diameter of $1360 \pm 295 \mathrm{~nm}$ at $120 \%$ (w/v) HPßCD solution in DMAc (Fig. 2h). When electrospun HP $\beta C D$ fibers obtained from DMAc were compared to the ones obtained from DMF, the diameter of the fibers produced from DMAc solution was thicker. The morphological and fiber diameter differences between the water and DMF system were related to the differences in the viscosity and conductivity of the solutions. Similarly, the $120 \%$ (w/v) HPBCD solution in DMAc has bigger aggregate size $(65.5 \mathrm{~nm})$, higher viscosity (0.329 Pa s) and much lower conductivity $\left(1.92 \mu \mathrm{S} \mathrm{cm} \mathrm{cm}^{-1}\right)$ when compared with $120 \%$ (w/v) HP $\beta C D$ solution in DMF (aggregate size: 20.6 $\mathrm{nm}$, viscosity: $0.234 \mathrm{~Pa} \mathrm{~s}$ and conductivity: $10.62 \mu \mathrm{S} \mathrm{cm} \mathrm{cm}^{-1}$ ); therefore, thicker HP $\beta C D$ fibers were produced in the case of the DMAc solvent system.

\section{Electrospinning of hydroxypropyl- $\gamma$-cyclodextrin $\left(\mathrm{HP}_{\gamma} \mathrm{CD}\right)$ fibers}

$\mathrm{HP} \gamma \mathrm{CD}$ is another type of chemically modified cyclodextrin derivative that was electrospun from water, DMF and DMAc solution systems. Similar to HPßCD, electrospinning was carried out by varying the HP $\gamma$ CD concentration from $100 \%$ to
$160 \%(\mathrm{w} / \mathrm{v})$ in water and from $100 \%$ to $125 \%(\mathrm{w} / \mathrm{v})$ in DMF and DMAc. The bead-free fibers were obtained at $160 \%(\mathrm{w} / \mathrm{v})$ concentration in water and at $125 \%$ (w/v) in DMF and DMAc (Fig. 4). The solution properties and the morphological findings of the fibers are summarized at Table 2. Unfortunately, the size of the $\mathrm{HP}_{\gamma} \mathrm{CD}$ aggregates cannot be measured accurately since these concentrated HP $\gamma$ CD solutions in water, DMF and DMAc have a slightly yellowish color and therefore we were unable to acquire accurate data from DLS measurements. Yet, the viscosity of the HP $\gamma$ CD solutions (Table 2) was much higher when compared to HP $\beta C D$ solutions (Table 1) suggesting that a substantial amount of aggregates was present in $\mathrm{HP} \gamma \mathrm{CD}$ solutions.

When $\mathrm{HP} \gamma \mathrm{CD}$ was electrospun from its aqueous solutions at low concentrations $(100 \%$ and $120 \%(\mathrm{w} / \mathrm{v}))$ only bead structures were formed (Fig. 4a and b). Increasing the concentration to $140 \%$ (w/v) yielded elongated beaded fibers (Fig. 4c) and finally bead-free fibers in the diameter range of 330-2100 $\mathrm{nm}$ having an average diameter of $1165 \pm 455 \mathrm{~nm}$ were obtained at $160 \%(\mathrm{w} / \mathrm{v})$ HP $\gamma$ CD concentration (Fig. 4d).

The optimal concentration was $125 \%(\mathrm{w} / \mathrm{v})$ for producing bead-free $\mathrm{HP}_{\gamma} \mathrm{CD}$ fibers (Fig. 4g) in DMF and the diameter range of the fibers was $1030-5800 \mathrm{~nm}(\mathrm{AFD}=2740 \pm 725 \mathrm{~nm})$. At $100 \%(\mathrm{w} / \mathrm{v})$ and $120 \%(\mathrm{w} / \mathrm{v})$, beaded fibers were obtained (Fig. $4 \mathrm{e}-\mathrm{f}$ ). Although the $120 \%$ (w/v) $\mathrm{HP} \gamma \mathrm{CD}$ solution in DMF has a reasonable viscosity, the beaded structures were not eliminated possibly because of the very low conductivity of the solution, therefore, higher solution concentration $(125 \%$, w/v)
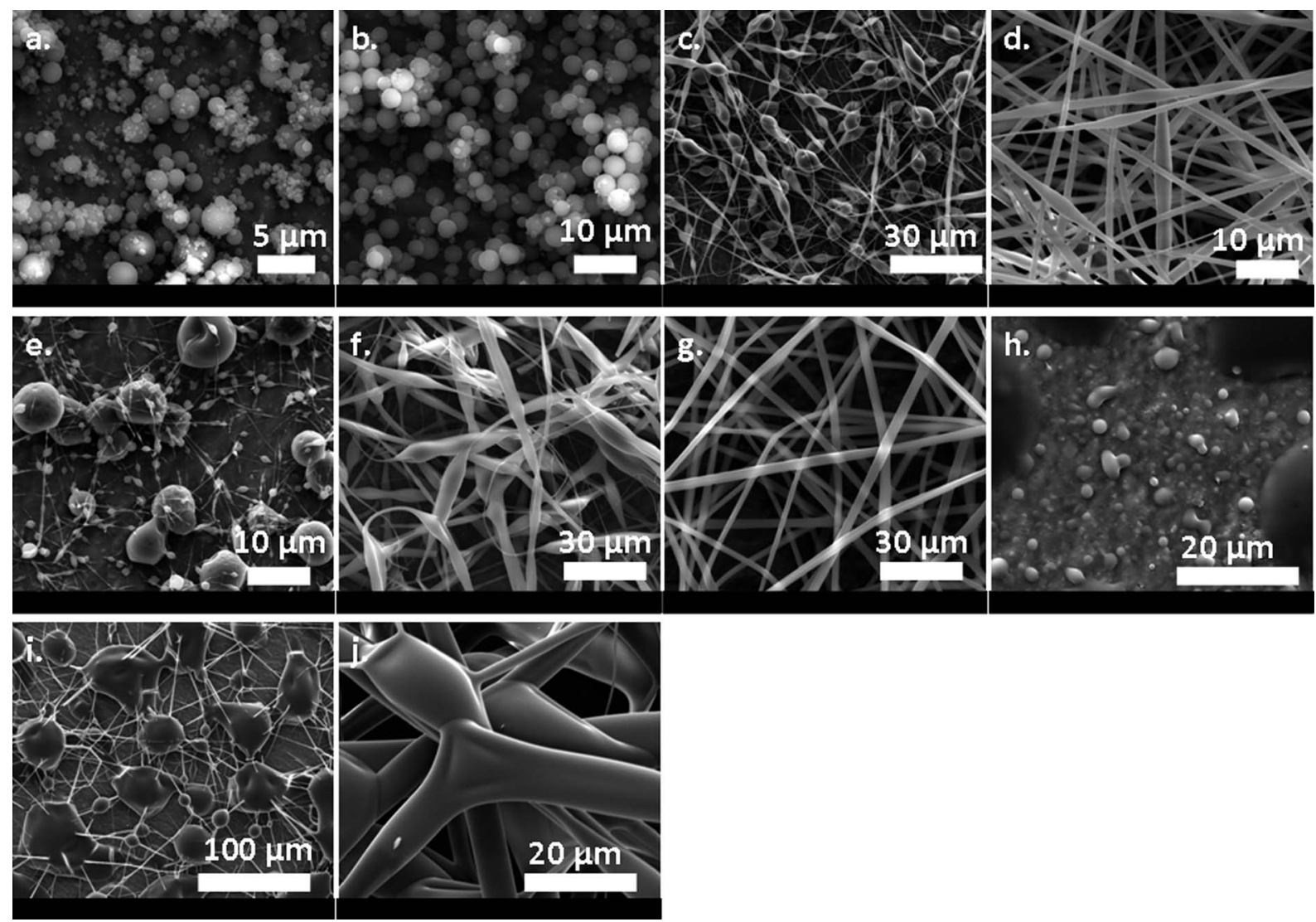

Fig. 4 The representative SEM images of the electrospun HP $\gamma$ CD nanofibers obtained from water, DMF and DMAc solutions having different HP $\gamma$ CD concentrations. (a) $100 \%$ (w/v), (b) $120 \%(w / v)$, (c) $140 \%$ (w/v) and (d) $160 \%(w / v) ~ H P \gamma C D$ in water; (e) $100 \%(w / v),(f) 120 \%(w / v)$ and (g) $125 \%$

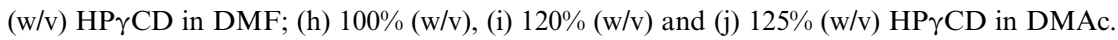


Table 2 The characteristics of HP $\gamma$ CD solutions, fiber morphology, average fiber diameter and fiber diameter range of the electrospun HP $\gamma \mathrm{CD}$ fibers

\begin{tabular}{|c|c|c|c|c|c|c|}
\hline Solutions & Solvent & $\begin{array}{l}(\%) \\
\mathrm{CD} / \mathrm{w} / \mathrm{v}\end{array}$ & $\begin{array}{l}\text { Viscosity/ } \\
\text { Pa s }\end{array}$ & $\begin{array}{l}\text { Conductivity/ } \\
\mu \mathrm{S} \mathrm{cm}^{-1}\end{array}$ & Fiber morphology & $\begin{array}{l}\text { Average fiber diameter/nm } \\
\text { (fiber diameter range/nm) }\end{array}$ \\
\hline $100 \% \mathrm{HP} \gamma \mathrm{CD}$ & Water & 100 & 0.0098 & 16.53 & Bead structure & - \\
\hline $140 \% \mathrm{HP} \gamma \mathrm{CD}$ & Water & 140 & 0.0398 & 9.61 & Beaded nanofibers & - \\
\hline $160 \% \mathrm{HP} \gamma \mathrm{CD}$ & Water & 160 & 0.0603 & 6.56 & Bead-free nanofibers & $1165 \pm 455(330-2100)$ \\
\hline $160 \% \mathrm{HP} \gamma \mathrm{CD}+20 \%$ urea & Water & 160 & 0.0547 & 8.58 & No fiber formation & - \\
\hline $100 \% \mathrm{HP} \gamma \mathrm{CD}$ & DMF & 100 & 0.0950 & 0.17 & Beaded nanofibers & - \\
\hline $125 \% \mathrm{HP} \gamma \mathrm{CD}+20 \%$ urea & DMF & 125 & 0.2940 & 0.07 & No fiber formation & - \\
\hline $100 \% \mathrm{HP} \gamma \mathrm{CD}$ & DMAc & 100 & 0.3390 & 0.07 & Bead structures & - \\
\hline $120 \% \mathrm{HP} \gamma \mathrm{CD}$ & DMAc & 120 & 1.6000 & 0.00 & Bead structures & - \\
\hline $125 \% \mathrm{HP}_{\gamma} \mathrm{CD}$ & DMAc & 125 & 1.6300 & 0.00 & Non-uniform fibers & $6385 \pm 1355(3600-9850)$ \\
\hline
\end{tabular}

was required for the formation of bead-free fibers. This behavior is commonly seen for the electrospinning of polymer solutions where higher polymer concentration is essential for solutions having low conductivity in order to eliminate the beads. ${ }^{1,9}$

The viscosity of the HP $\gamma$ CD solution in DMAc was considerably higher than the ones in water and DMF and the conductivity of the solution was zero (Table 2). Beads and splashes were formed at $100 \%$ (w/v) (Fig. 4h) and beaded fibers along with some splashes were obtained when $120 \%$ (w/v) HP $\gamma$ CD solution was electrospun (Fig. 4i). The electrospinning of $125 \%$ (w/v) HP $\gamma \mathrm{CD}$ solution in DMAc resulted in very thick non-uniform fibers (Fig. 4j). Due to the very high viscosity and zero solution conductivity, the stretching of the jet was minimal and the HP $\gamma \mathrm{CD}$ micron-sized fibers in the diameter range of 3600-9850 $\mathrm{nm}(\mathrm{AFD}=6385 \pm 1355$ $\mathrm{nm}$ ) were formed. In addition, some of the fibers were fused together indicating that the solvent evaporation was not completed during the electrospinning of the fibers. This is possibly because of the low volatility of DMAc and a very high viscosity of the HP $\gamma$ CD solution (Table 2). DMAc $\left(T_{\mathrm{b}}=165^{\circ} \mathrm{C}\right)$ has a higher boiling point than $\mathrm{DMF}\left(T_{\mathrm{b}}=153^{\circ} \mathrm{C}\right)$ and water $\left(T_{\mathrm{b}}=100^{\circ} \mathrm{C}\right)$, hence, its evaporation at room temperature cannot be completed thus wet fibers having junctions within the touching points of the fibers were obtained.

When the fiber diameters are compared, $\mathrm{HP} \gamma \mathrm{CD}$ fibers are much thicker than the HP $\beta C D$ fibers due to the much higher viscosity and very low conductivity of the HP $\gamma \mathrm{CD}$ solutions. The solution conductivity is one of the main parameters in the electrospinning process since the viscous solution is being stretched due to the repulsion of the charges present on its surface. ${ }^{1}$ The charge density of the solution is higher in the case of higher solution conductivity, which causes a greater repulsion and a greater bending instability during electrospinning, and therefore the jet is subjected to more stretching under the high electrical field and resulted in thinner fibers. ${ }^{1}$ Here, micron-sized fibers were obtained from HP $\gamma$ CD because of the high viscosity and very low conductivity of the HP $\gamma \mathrm{CD}$ solutions.

\section{Electrospinning of methyl- $\beta$-cyclodextrin $(\mathrm{M} \beta \mathrm{CD})$ nanofibers}

$\mathrm{M} \beta \mathrm{CD}$ is the methylated derivative of $\beta$-cyclodextrin and it has very high solubility like hydroxypropyl cyclodextrins. In our previous communication, we have demonstrated that $\mathrm{M} \beta \mathrm{CD}$ nanofibers can be electrospun without the addition of a polymeric carrier matrix. ${ }^{33}$ The solution properties of $\mathrm{M} \beta C D$ in water, DMF and DMAc and the morphological findings of the resulting electrospun nanofibers are given in Table 3. The DLS measurements indicated that the size of M $B C D$ aggregates became larger as the solution concentration increased from $100 \%$ to $160 \%(w / v)$ in water and DMF (Fig. 5). The M $\beta C D$ aggregates were larger in DMF solutions when compared to the water solutions in all concentrations. In the case of M $\beta C D$ in DMAc solutions, we were unable to obtain reasonable data from DLS measurements since the solutions were slightly turbid, but the viscosity of the $\mathrm{M} \beta C D$ solutions was higher compared to the viscosities in water and DMF suggesting that a larger amount of $\mathrm{M} \beta \mathrm{CD}$ aggregates were present in DMAc solutions.

Electrospinning of $100 \%$ and $120 \%(w / v)$ M $\beta C D$ aqueous solutions yielded elongated bead structures (Fig. 6a) and beaded nanofibers (Fig. 6b), respectively. These results suggested the presence of inadequate aggregations in the $\mathrm{M} \beta \mathrm{CD}$ solution. On the other hand, uniform nanofibers having fiber diameters in the range of $20-490 \mathrm{~nm}(A F D=95 \pm 90 \mathrm{~nm})$ and $20-650 \mathrm{~nm}$ $(\mathrm{AFD}=100 \pm 140 \mathrm{~nm})$ were produced at $140 \%$ and $160 \%(\mathrm{w} / \mathrm{v})$ concentrations, respectively, indicating that a sufficient aggregation level was achieved at these concentrations.

At lower M $\beta C D$ concentration $(100 \%(w / v))$ in DMF, micron and nano-size droplets were formed (Fig. 6e), but, once the $120 \%$ (w/v) M $\beta C D$ solution was electrospun, ultrafine fibers with a considerable amount of beads were obtained (Fig. 6f). The transition from beaded nanofibers to bead-free nanofibers was observed when 140\% (w/v) and 160\% (w/v) M $\beta C D$ solutions were electrospun (Fig. $6 \mathrm{~g}$ and $\mathrm{h}$ ). Bead-free nanofibers having fiber diameters in the range of $100-1000 \mathrm{~nm}(\mathrm{AFD}=430 \pm 170$ $\mathrm{nm})$ and $100-1200 \mathrm{~nm}(\mathrm{AFD}=450 \pm 200 \mathrm{~nm})$ were obtained at $140 \%$ and $160 \%(\mathrm{w} / \mathrm{v})$ concentrations, respectively.

In the case of using DMAc as a solvent, $100 \%$ and $120 \%(\mathrm{w} / \mathrm{v})$ $\mathrm{M} \beta \mathrm{CD}$ solutions yielded nano- and micron-size beads (Fig. 6i-j). At $140 \%(w / v)$, nanofibers with vastly beaded structures were obtained (Fig. 6k) and increasing the $\mathrm{M} \beta \mathrm{CD}$ concentration to $160 \%$ (w/v) yielded bead-free nanofibers (Fig. 61). When the fiber diameters were compared with the ones obtained from water and DMF solution systems, it was found that thicker fibers in the range of 430-2450 $\mathrm{nm}(\mathrm{AFD}=1200 \pm 555 \mathrm{~nm})$ were produced because of the higher viscosity and lower conductivity values of the M $\beta C D$ solution in DMAc.

When compared with $\mathrm{HP} \beta \mathrm{CD}$ and $\mathrm{HP} \gamma \mathrm{CD}, \mathrm{M} \beta \mathrm{CD}$ nanofibers obtained from water noticeably have much smaller diameter. The possible reason is the smaller aggregate size, low 
Table 3 The characteristics of M $\beta C D$ solutions, fiber morphology, average fiber diameter and fiber diameter range of the electrospun M $\beta C D$ fibers. DLS measurements of $\mathrm{M} \beta C D$ solutions at $25^{\circ} \mathrm{C}$ summarizing the average diameter (nm) and polydispersity index (PDI) of M $\beta C D$ aggregates

\begin{tabular}{|c|c|c|c|c|c|c|c|c|}
\hline Solutions & Solvent & $\begin{array}{l}(\%) \\
\mathrm{CD} / \mathrm{w} / \mathrm{v}\end{array}$ & $\begin{array}{l}\text { Viscosity/ } \\
\mathrm{Pa} \mathrm{s}\end{array}$ & $\begin{array}{l}\text { Conductivity/ } \\
\mu \mathrm{S} \mathrm{cm}-1\end{array}$ & $\begin{array}{l}\text { Intensity-average } \\
\text { diameter } / d, \mathrm{~nm}\end{array}$ & PDI & Fiber morphology & $\begin{array}{l}\text { Average fiber diameter/nm } \\
\text { (fiber diameter range/nm) }\end{array}$ \\
\hline $100 \% \mathrm{M} \beta \mathrm{CD}$ & Water & 100 & 0.0116 & 1842 & 5.9 & 0.32 & Bead structures & - \\
\hline $140 \% \mathrm{M} \beta \mathrm{CD}$ & Water & 140 & 0.0509 & 1177 & 7.6 & 0.41 & Bead-free nanofibers & $95 \pm 90(20-490)$ \\
\hline $160 \% \mathrm{M} \beta \mathrm{CD}$ & Water & 160 & 0.1060 & 979 & 9.0 & 0.55 & Bead-free nanofibers & $100 \pm 140(20-650)$ \\
\hline $160 \% \mathrm{M} \beta C \mathrm{CD}+20 \%$ urea & Water & 160 & 0.0061 & 780 & 6.5 & 0.30 & No fiber formation & - \\
\hline $100 \% \mathrm{M} \beta \mathrm{CD}$ & DMF & 100 & 0.0176 & 46.20 & 6.3 & 0.25 & Sphere structures & - \\
\hline $160 \% \mathrm{M} \beta \mathrm{CD}$ & DMF & 160 & 0.5640 & 12.87 & 13.7 & 0.36 & Bead-free nanofibers & $450 \pm 200(100-1200)$ \\
\hline $160 \% \mathrm{M} \beta \mathrm{CD}+20 \%$ urea & DMF & 160 & 0.4420 & 12.96 & 6.2 & 0.22 & No fiber formation & - \\
\hline $100 \% \mathrm{M} \beta \mathrm{CD}$ & DMAc & 100 & 0.0331 & 4.76 & - & - & Sphere structures & - \\
\hline $120 \% \mathrm{M} \beta \mathrm{CD}$ & DMAc & 120 & 0.1220 & 2.33 & - & - & Bead structures & - \\
\hline $140 \% \mathrm{M} \beta \mathrm{CD}$ & DMAc & 140 & 0.2550 & 1.54 & - & - & Beaded nanofibers & - \\
\hline $160 \% \mathrm{M} \beta \mathrm{CD}$ & DMAc & 160 & 0.5330 & 1.39 & - & - & Bead-free nanofibers & $1200 \pm 555(430-2450)$ \\
\hline
\end{tabular}

viscosity and very high conductivity of the $\mathrm{M} \beta \mathrm{CD}$ solutions in water (Table 3) which yielded much thinner fibers because of the increased stretching of the jet during the electrospinning. Similar results were also obtained from the electrospinning of $\mathrm{M} \beta C D$ solutions in DMF and DMAc which yielded thinner M $\beta C D$ fibers when compared to HP $\beta C D$ and HP $\gamma C D$ fibers. This behavior is very similar to the electrospinning of polymer solutions in which solutions having low viscosity and high conductivity yield thinner fibers. ${ }^{1}$

\section{The effect of urea on the electrospinning of CD nanofibers}

It is known that the addition of urea to $C D$ solutions causes notable depression of the self-association of the CD molecules since urea breaks up the hydrogen bonds between the CD molecules. ${ }^{35,36}$ Here, we added $20 \%$ urea (w/w, with respect to CD) to $160 \%(\mathrm{w} / \mathrm{v}) \mathrm{HP} \beta \mathrm{CD}, 160 \%(\mathrm{w} / \mathrm{v}) \mathrm{HP} \gamma \mathrm{CD}$ and $160 \%(\mathrm{w} / \mathrm{v})$ $\mathrm{M} \beta C \mathrm{CD}$ in water solutions and to $120 \%$ (w/v) HP $\beta C D, 125 \%$ (w/v) $\mathrm{HP}_{\gamma} \mathrm{CD}$ and $160 \% \mathrm{M} \beta \mathrm{CD}(\mathrm{w} / \mathrm{v})$ in DMF solutions. The insolubility of urea in DMAc restricted the investigation of urea effect on the electrospinning of these CDs in a DMAc solvent system. The DLS and viscosity measurements clearly showed that the size of the CD aggregates became smaller and the viscosity of the solutions was decreased after the addition of urea which was due to the destruction of the $\mathrm{CD}$ aggregates in their solutions (Fig. 3 and 5, Tables 1-3). The electrospinning of CD solutions containing urea yielded no fibers but only beads or splashes. Fig. 7 shows the representative SEM images of splashed areas or beads which were obtained from the electrospinning of urea containing CD solutions. This is because of the breakup of the electrospinning jet due to the presence of inadequate $\mathrm{CD}$ aggregates in the solutions. This result further proved that the success of electrospinning of fibers from cyclodextrins was due to the presence of intermolecular interactions and sufficient aggregates in their highly concentrated solutions.

\section{Characterization of the electrospun CD nanowebs}

The structural analyses of the electrospun CD nanowebs were performed by X-ray diffraction (XRD). Native CDs ( $\alpha-C D, \beta$ $\mathrm{CD}$ and $\gamma-\mathrm{CD}$ ) are crystalline, however, random substitution of the hydroxyl groups of CDs with methyl or hydroxypropyl groups resulted in amorphous materials. The XRD studies showed that the diffraction patterns of all the electrospun CD nanowebs are very similar to their powder form having amorphous structure (Fig. 8). No additional diffraction peaks and/or sharpening of the present peaks were observed indicating the absence of any particular orientations of CD molecules during the fiber formation.

Thermogravimetric analyses (TGA) showed minor weight losses between 25 and $100{ }^{\circ} \mathrm{C}$ which was due to the removal of water from the $\mathrm{CD}$ nanowebs (Fig. 9). From the TGA data, it was calculated that the HP $\beta C D$ and $M \beta C D$ nanowebs contained $\sim 5 \%$ and $\sim 2$ to $3 \%(\mathrm{w} / \mathrm{w})$ of water, respectively. In the case of
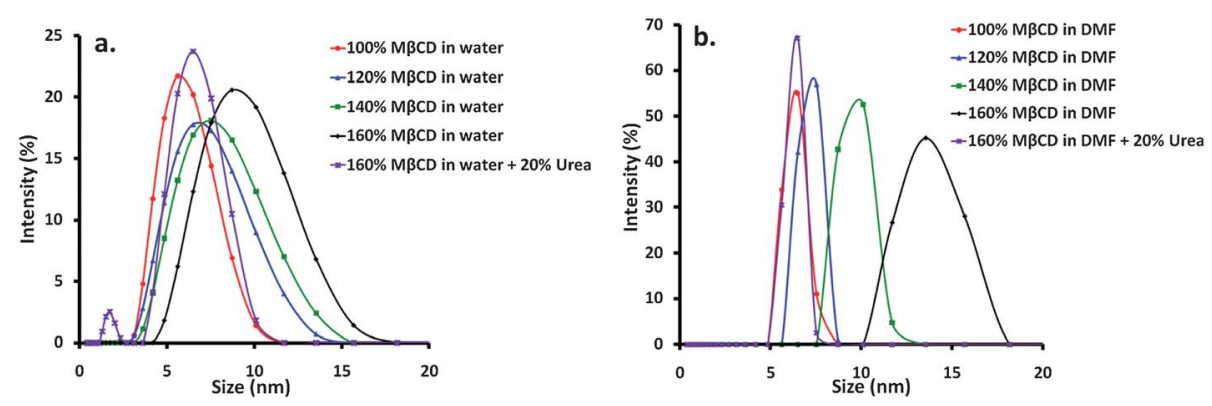

Fig. 5 Size distribution of M $\beta C D$ aggregates for (a) 100\%, 120\%, 140\%, 160\% (w/v) M $\beta C D$ and 160\% (w/v) M $\beta C D$ containing 20\% (w/w) urea in water; and (b) $100 \%, 120 \%, 140 \%, 160 \%$ (w/v) M $\beta C D$ and $160 \%$ (w/v) M $\beta C D$ containing $20 \%(w / w)$ urea in DMF. 

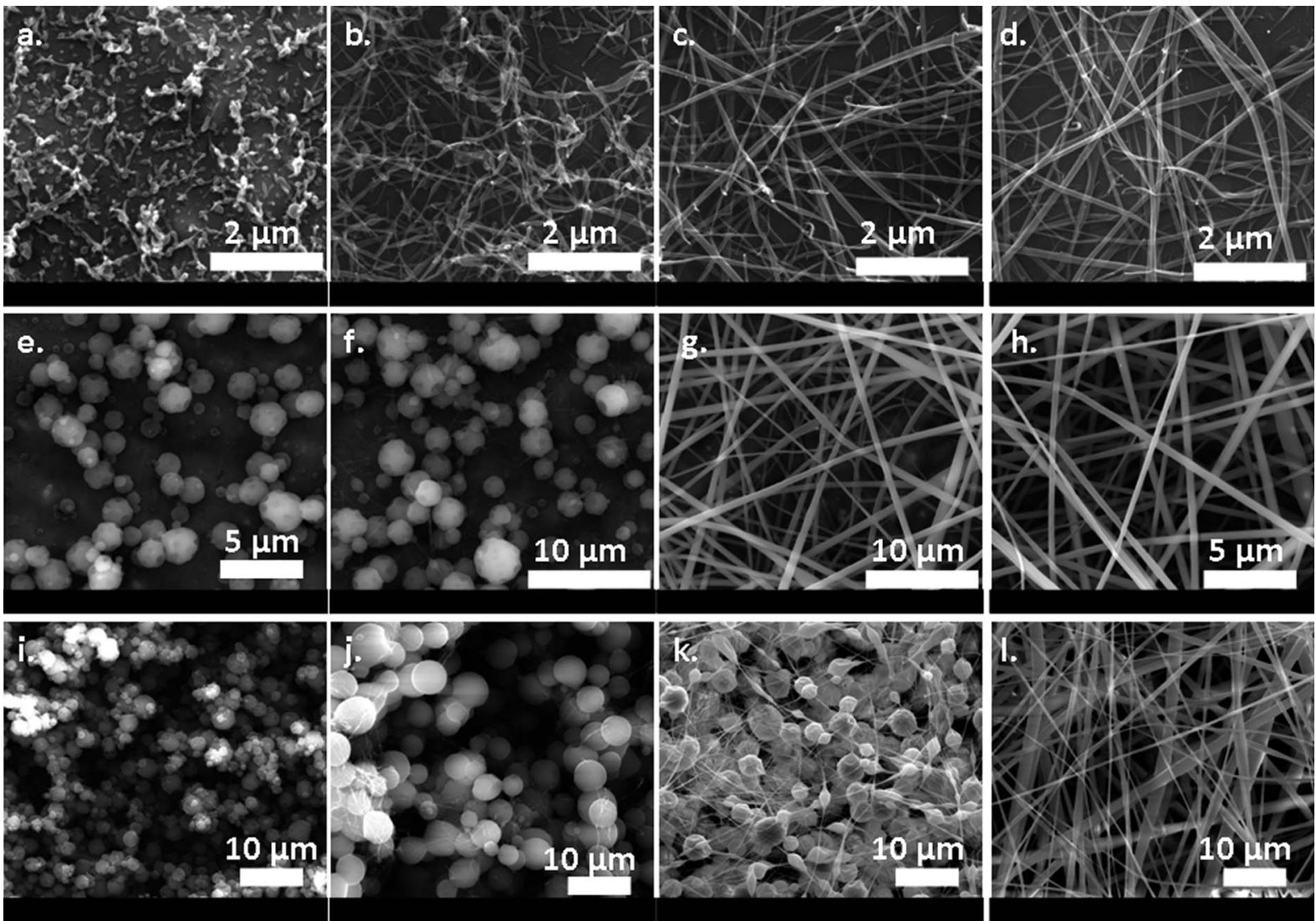

Fig. 6 The representative SEM images of the electrospun M $\beta C D$ nanofibers obtained from water, DMF and DMAc solutions having different M $\beta C D$ concentrations. (a) 100\% (w/v), (b) 120\% (w/v), (c) 140\% (w/v) and (d) 160\% (w/v) M 3 CD in water; (e) 100\% (w/v), (f) 120\% (w/v), (g) 140\% (w/v), and (h) $160 \%$ (w/v) M $\beta$ CD in DMF; and (i) $100 \%$ (w/v), (j) $120 \%$ (w/v), (k) $140 \%$ (w/v) and (l) $160 \%$ (w/v) M $\beta C D$ in DMAc.

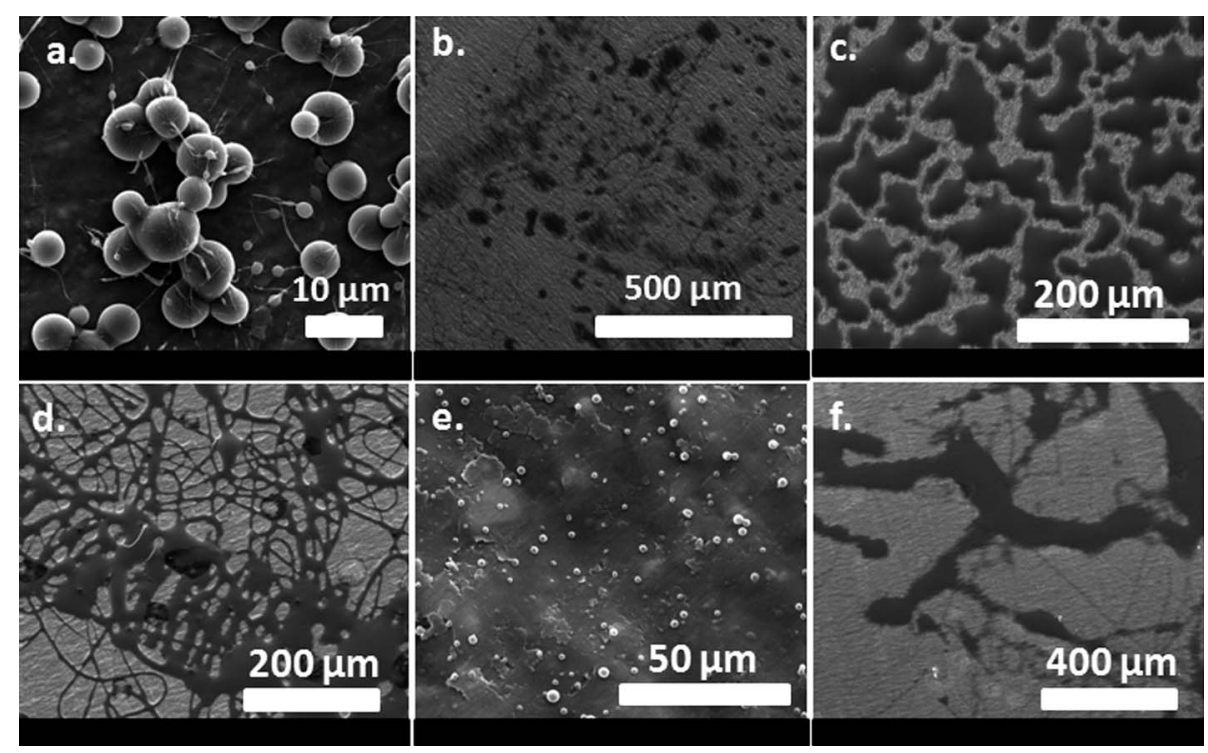

Fig. 7 The representative SEM images of the splashed area that were obtained as a result of adding $20 \%$ (w/w) urea to CD solutions. (a) $160 \%$ (w/v) HP $\beta C D$ containing 20\% (w/w) urea in water, (b) $120 \%$ (w/v) HP 3 CD containing $20 \%$ (w/w) urea in DMF, (c) $160 \%$ (w/v) HP $\gamma$ CD containing $20 \%$ (w/w) urea in water, (d) $125 \%$ (w/v) HP $\gamma$ CD containing 20\% (w/w) urea in DMF, (e) $160 \%$ (w/v) M $\beta C D$ containing $20 \%$ (w/w) urea in water, and (f) $160 \%$ (w/v) M $\beta C D$ containing $20 \%(w / w)$ urea in DMF. 

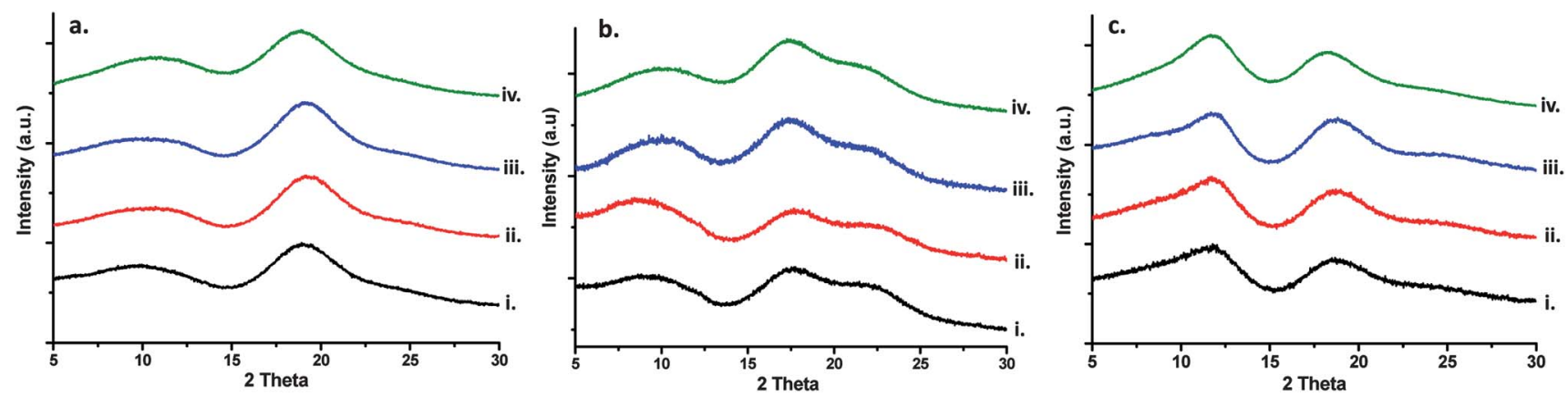

Fig. 8 XRD patterns of (a) the HPßCD nanoweb produced from (i) water, (ii) DMF, (iii) DMAc solution and (iv) as-received HP $\beta C D$ powder; (b) the $\mathrm{HP} \gamma \mathrm{CD}$ web produced from (i) water, (ii) DMF, (iii) DMAc solution and (iv) as-received HP $\gamma$ CD powder; and (c) the M $\beta C D$ nanoweb produced from (i) water, (ii) DMF, (iii) DMAc solution and (iv) as-received $M \beta C D$ powder.
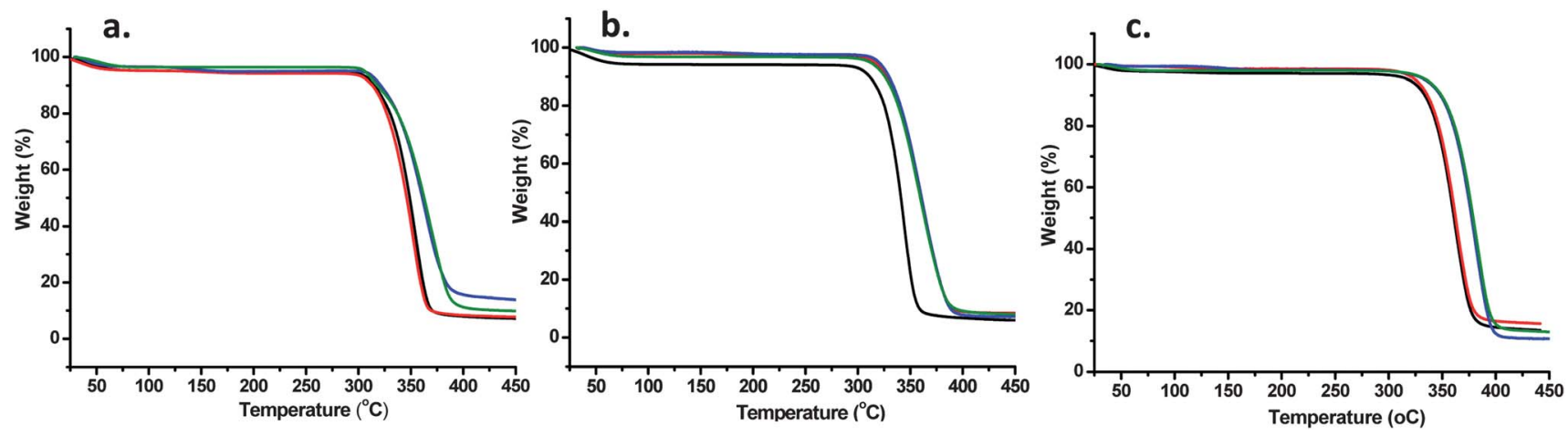

Fig. 9 TGA thermograms of (a) the HPßCD nanoweb produced from water (black line), DMF (red line), DMAc (blue line) and the as-received powder form of HPßCD (green line); (b) the HP $\gamma \mathrm{CD}$ web produced from water (black line), DMF (red line), DMAc (blue line) and the as-received powder form of $\mathrm{HP} \gamma \mathrm{CD}$ (green line); and (c) M $\beta C D$ nanoweb produced from water (black line), DMF (red line), DMAc (blue line) and the as-received powder form of $\mathrm{M} \beta \mathrm{CD}$ (green line).

$\mathrm{HP}_{\gamma} \mathrm{CD}$, the water content was about $\sim 5 \%$ and $\sim 2 \%(\mathrm{w} / \mathrm{w})$ for the nanowebs produced from water, and from DMF and DMAc solvent systems, respectively. For all the CD nanowebs (HP $\beta C D$, $\mathrm{HP} \gamma \mathrm{CD}$, and $\mathrm{M} \beta \mathrm{CD}$ ), the main thermal degradation was between 300 and $350{ }^{\circ} \mathrm{C}$. However, it was observed that the onset temperature of the main degradation was slightly different for $\mathrm{CD}$ nanowebs electrospun from different solvent systems. When compared to as-received CD powder, the main thermal degradation was observed at a slightly lower temperature for HP $\beta C D$ nanowebs electrospun from water and DMF, HP $\gamma \mathrm{CD}$ nanowebs electrospun from water, and M $\beta C D$ nanowebs electrospun from water and DMF. This is possible due to the thinner fiber diameter of the CD nanowebs which have higher surface area and higher contact points resulting in slightly earlier thermal degradation compared to powder CDs. The TGA thermograms of $\mathrm{HP} \beta C D, \mathrm{HP}_{\gamma} \mathrm{CD}$, and $\mathrm{M} \beta \mathrm{CD}$ nanowebs electrospun from DMAc and $\mathrm{HP} \gamma \mathrm{CD}$ nanowebs electrospun from DMF were very similar to those of powder CDs. These CD webs have much thicker fiber diameter and presumably the surface areas of these webs were not much different than the $\mathrm{CD}$ powder and therefore showed very similar thermal behavior.

The mechanical strength of the electrospun CD nanowebs was also examined visually. These electrospun $\mathrm{CD}$ nanowebs are consisting of small molecules having amorphous structure, and therefore, they are expected to be very weak and brittle when compared to polymeric systems. Nonetheless, the HPßCD and $M \beta C D$ electrospun nanowebs obtained from three different solvent systems (water, DMF and DMAc) have shown some mechanical strength and flexibility by which they can be easily handled and folded as free standing materials (Fig. 10). In the case of $\mathrm{HP} \gamma \mathrm{CD}$, nanowebs electrospun from water were similar to $\mathrm{HP} \beta C D$ and $\mathrm{M} \beta \mathrm{CD}$, but, $\mathrm{HP} \gamma \mathrm{CD}$ nanowebs obtained from DMF and DMAc solutions have more brittle nature and therefore it was difficult to handle them (Fig. 10e and f). This suggested that the mechanical properties of $\mathrm{HP}_{\gamma} \mathrm{CD}$ nanowebs were significantly depending on the type of the solvent used for the electrospinning.

\section{Conclusions}

Electrospinning of nanofibers involves high molecular weight polymers and high polymer concentrations since polymer chain entanglements are very crucial for sustaining the electrified jet and therefore resulting in bead-free uniform fibers. So, the electrospinning of nanofibers from CDs is very challenging since these are small molecules having a cone-shaped molecular structure. Yet, in this study, we were very successful at producing polymer-free ultrafine fibers from three different $\mathrm{CD}$ derivatives- $\mathrm{H} \beta \mathrm{CD}, \mathrm{H} \gamma \mathrm{CD}$ and $\mathrm{M} \beta \mathrm{CD}$ in three different solvent systems, water, DMF and DMAc, via electrospinning. The 

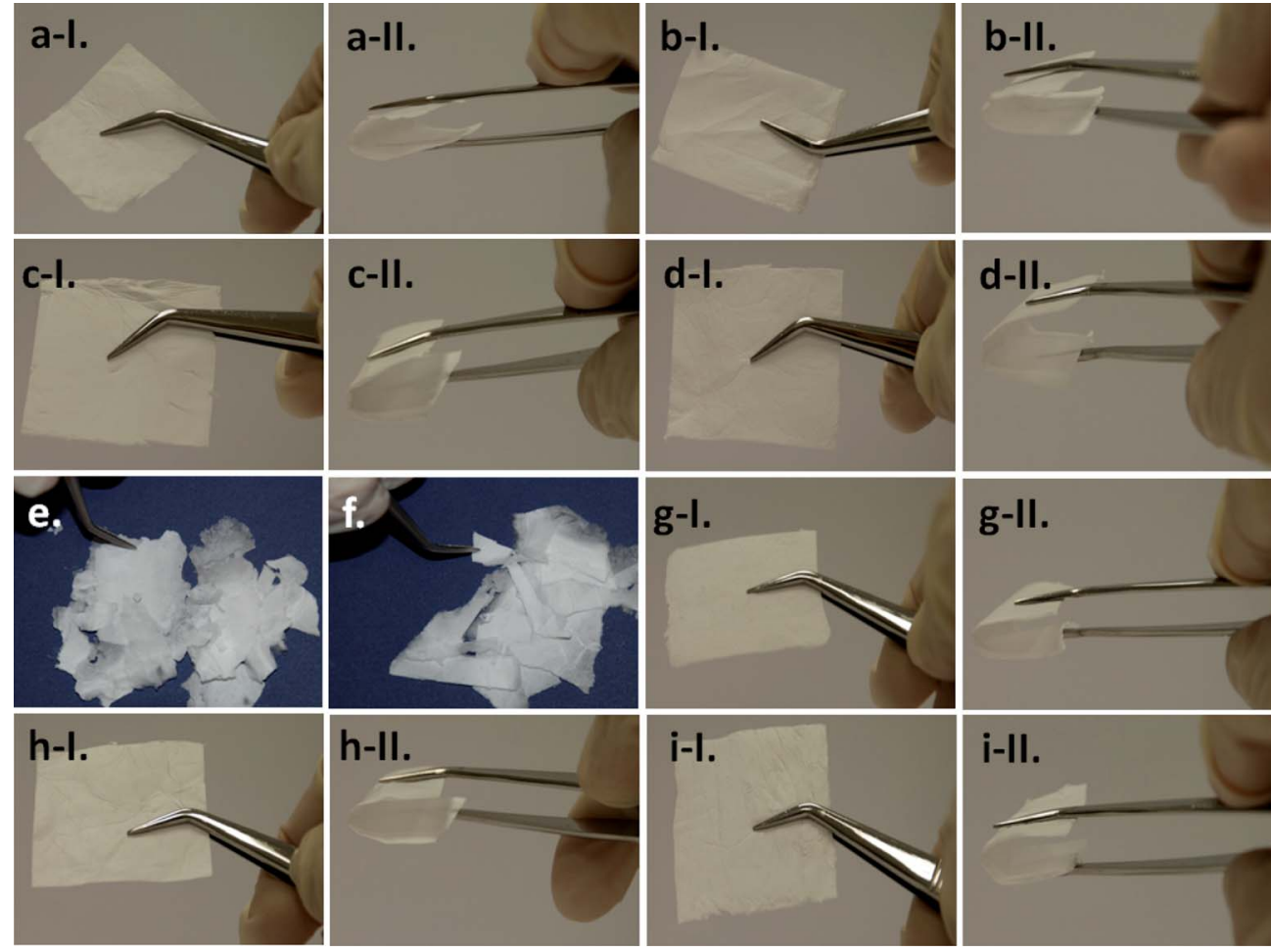

Fig. 10 Nanowebs obtained from (a-I and II) $160 \%$ (w/v) HPßCD in water; (b-I and II) $120 \%$ (w/v) HP $\beta C D$ in DMF; (c-I and II) $120 \%$ (w/v) HP $\beta C D$ in

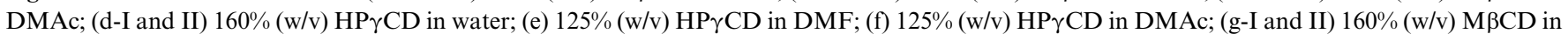
water; (h-I and II) $160 \%$ (w/v) M $\beta C D$ in DMF; and (i-I and II) $160 \%$ (w/v) M $\beta C D$ in DMAc. Photographs show that the nanowebs have mechanical integrity and they can be easily handled and folded as a free-standing web except for the HP $\gamma \mathrm{CD}$ web produced from DMF and DMAc.

success of the electrospinning of polymer-free fibers from these $\mathrm{CD}$ derivatives is due to the presence of considerable aggregates and intermolecular interactions between the CD molecules in their concentrated solutions in which these aggregates and interactions can effectively stabilize the jet and therefore resulted in bead-free nanofibers when electrospun. The electrospinning of $\mathrm{CD}$ solutions containing urea yielded only beads or splashes instead of fibers since urea breaks the hydrogen bonds between the $\mathrm{CD}$ molecules and therefore destroys the $\mathrm{CD}$ aggregates in their solutions.

The optimization of the electrospinning of the bead-free nanofibers from $\mathrm{H} \beta C \mathrm{CD}, \mathrm{H} \gamma \mathrm{CD}$ and $\mathrm{M} \beta \mathrm{CD}$ was carried out extensively in three different solvent systems (water, DMF and DMAc) by varying solution concentrations from $100 \%$ to $160 \%$ $(w / v)$. We observed that the morphologies and the thickness of the electrospun fibers were highly dependent on the CD derivatives and the type of solvent system used. Only CD solutions having optimal concentration/viscosity and conductivity values were able to be electrospun into bead-free fibers. CD nanofibers electrospun from water solutions were much thinner when compared with the ones electrospun from DMF and DMAc solvent systems because of the low viscosity and high conductivity of the $\mathrm{CD}$ solutions in water. Micron-sized CD fibers were obtained in the case of the DMAc solvent system due to the high viscosity and very low conductivity of the solutions as well as the low evaporation rate of the solvent. Our results indicated that electrospinning of these $\mathrm{CDs}$ is quite similar to polymeric systems where the high solution concentration/viscosity and high solution conductivity are very crucial for obtaining bead-free nanofibers from CDs.

The visual observations revealed that these $\mathrm{CD}$ nanowebs have some mechanical integrity and they can be easily handled and folded as a free standing web. Thus, these CD nanofibers/ nanowebs would be particularly attractive due to the exclusive properties obtained by combining the very large surface area of nanofibers with specific functionality of the CDs. CDs are already being used in pharmaceuticals, functional foods, textiles, filtrations, and sustained/controlled delivery systems, therefore, having nanofiber/nanoweb structures might hopefully open up the possibilities and extend the use of $\mathrm{CDs}$ in the fields of biotechnology, food, textiles, and filtration or in other functional systems. Moreover, our findings may lead to the fabrication of new functional nanofibers from other types of cyclodextrins and/ or other supramolecular systems via electrospinning.

\section{Experimental}

\section{Materials}

Hydroxypropyl- $\beta$-cyclodextrin ((HP $\beta C D)$, molar substitution: $0.6-0.9)$, hydroxypropyl- $\gamma$-cyclodextrin $((\mathrm{HP} \gamma \mathrm{CD})$, molar substitution: $0.5-0.7)$ and methyl- $\beta$-cyclodextrin ((MBCD), molar substitution: 1.6-1.9) were purchased from Wacker Chemie AG, Germany. N,N-Dimethylformamide (DMF) (Riedel, Pestenal), dimethylacetamide (DMAc) (Sigma-Aldrich, $99 \%$ ) and urea (Merk, $>99.5 \%$ ) were purchased. The water used 
was from a Millipore Milli-Q Ultrapure Water System. All the materials were used without any purification.

\section{Electrospinning}

The solutions of HP $\beta C D, H P \gamma C D$ and $M \beta C D$ were prepared in various concentrations $(100 \%(\mathrm{w} / \mathrm{v})$ to $160 \%(\mathrm{w} / \mathrm{v}))$ by using water, DMF and DMAc as solvent systems. The clear and homogeneous $\mathrm{CD}$ solutions were obtained after stirring for 1 hour at $50{ }^{\circ} \mathrm{C}$ and additional stirring for 30 minutes at room temperature. To see the effect of urea on the fiber formation, $20 \%$ (w/w, with respect to $\mathrm{CD}$ ) urea was added into the CD solutions of water and DMF at the optimized CD concentrations. Since urea has a very limited solubility in DMAc, we were unable to study the effect of urea on the electrospinning of CDs from DMAc solutions. The CD solutions were loaded in $1 \mathrm{ml}$ syringes (metallic needle with 0.45 inner diameter), thereafter, positioned horizontally on the syringe pump (Model: SP 101IZ, WPI). The electrode of the high voltage power supply (Matsusada Precision, AU Series) was clamped to the metal needle tip and the cylindrical aluminium collector was grounded. The electrospinning of the $\mathrm{CD}$ solutions was performed at the following parameters: applied voltage $=15 \mathrm{kV}$, tip-to-collector distance $=15 \mathrm{~cm}$ and the solution flow rate $=0.5 \mathrm{ml} \mathrm{h}^{-1}$. Electrospun $\mathrm{CD}$ fibers were deposited on a grounded stationary cylindrical metal collector covered by a piece of aluminium foil. The electrospinning apparatus was enclosed in a Plexiglas box and the electrospinning was carried out at $25^{\circ} \mathrm{C}$ at $30 \%$ relative humidity. The $\mathrm{CD}$ nanofibers/nanowebs were dried at $60^{\circ} \mathrm{C}$ in the vacuum oven overnight in order to remove the residual solvent if present.

\section{Measurements and characterization}

The viscosity measurements of the $\mathrm{CD}$ solutions were performed with a rheometer (Physica MCR 301, Anton Paar) equipped with a cone/plate accessory at a constant shear rate of $1001 \mathrm{~s}^{-1}$ at 22 ${ }^{\circ} \mathrm{C}$. The particle size of the aggregates in $\mathrm{CD}$ solutions was measured by a Nano-ZS Zetasizer dynamic light scattering (DLS) system (Malvern Instruments). The equilibrium at $25^{\circ} \mathrm{C}$ for 2 minutes was applied prior to DLS measurements of the CD solutions. The conductivity of the CD solutions was measured with a Multiparameter meter InoLab® Multi 720 (WTW) at room temperature. The morphology and the diameter of the CD nanofibers were investigated by a scanning electron microscope (SEM) (Quanta 200 FEG, FEI). The average fiber diameters (AFDs) were calculated by analyzing around 100 fibers from the SEM images. Prior to SEM imaging, samples were coated with 5 $\mathrm{nm} \mathrm{Au/Pd} \mathrm{(PECS-682).} \mathrm{The} \mathrm{X-ray} \mathrm{diffraction} \mathrm{(XRD)} \mathrm{(X'Pert}$ powder diffractometer, PANalytical) studies of CD nanofibers were performed by using $\mathrm{Cu} \mathrm{K} \alpha$ radiation in a range of $2 \theta=5-$ $30^{\circ}$. A thermogravimetric analyzer (TGA) (Q500, TA Instruments) was used for the investigation of the thermal properties of the CD nanofibers. TGA of the samples was carried out from 25 ${ }^{\circ} \mathrm{C}$ to $500{ }^{\circ} \mathrm{C}$ at a $20{ }^{\circ} \mathrm{C} \mathrm{min}^{-1}$ heating rate and $\mathrm{N}_{2}$ was used as a purge gas.

\section{Acknowledgements}

State Planning Organization (DPT) of Turkey is acknowledged for the support of UNAM-Institute of Materials Science \& Nanotechnology. Dr T. Uyar acknowledges EU FP7-PEOPLE2009-RG Marie Curie-IRG for funding the NANOWEB (PIRG06-GA-2009-256428) project. A. Celebioglu acknowledges TUBITAK-BIDEB for the national graduate study scholarship.

\section{References}

1 S. Ramakrishna, K. Fujihara, W. Teo, T. Lim and Z. Ma, in $A n$ Introduction to Electrospinning and Nanofibers, World Scientific Publishing Company, 2005.

2 A. Greiner and J. Wendorff, Angew. Chem., Int. Ed., 2007, 46, 5670.

3 J. Xie, M. R. MacEwan, A. G. Schwartz and Y. Xia, Nanoscale, 2010, 2,35 .

4 H. Fong, I. Chun and D. H. Reneker, Polymer, 1999, 40, 4585.

5 K. H. Lee, H. Y. Kim, H. J. Bang, Y. H. Jung and S. G. Lee, Polymer, 2003, 44, 4029.

6 C. L. Casper, J. S. Stephens, N. G. Tassi, D. B. Chase and J. F. Rabolt, Macromolecules, 2004, 37, 573.

7 P. Gupta, C. Elkins, T. E. Long and G. L. Wilkes, Polymer, 2005, 46, 4799.

8 S. L. Shenoy, W. D. Bates, H. L. Frisch and G. E. Wnek, Polymer, 2005, 46, 3372.

9 T. Uyar and F. Besenbacher, Polymer, 2008, 49, 5336.

10 J. H. Yu, S. V. Fridrikh and G. C. Rutledge, Polymer, 2006, 47, 4789.

11 C.-L. Pai, M. C. Boyce and G. C. Rutledge, Macromolecules, 2009, 42, 2102.

12 C. Wang, H.-S. Chien, C.-H. Hsu, Y.-C. Wang, C.-T. Wang and H.-A. Lu, Macromolecules, 2007, 40, 7973.

13 S. Ramakrishna, K. Fujihara, W. E. Teo, T. Yong, Z. Ma and R. Ramaseshan, Mater. Today, 2006, 9, 40.

14 V. Thavasi, G. Singh and S. Ramakrishna, Energy Environ. Sci., 2008, 1, 205.

15 K. Yoon, B. Hsiao and B. Chu, J. Mater. Chem., 2008, 18, 5326.

16 J. Xie, X. Li and Y. Xia, Macromol. Rapid Commun., 2008, 29, 1775.

17 T. Uyar, R. Havelund, J. Hacaloglu, F. Besenbacher and P. Kingshott, ACS Nano, 2010, 4, 5121.

18 F. Yao, L. Xu, B. Lin and G.-D. Fu, Nanoscale, 2010, 2, 1348.

19 J. Szejtli, Chem. Rev., 1998, 98, 1743.

20 A. Hedges, Chem. Rev., 1998, 98, 2035.

21 M. Davis and M. Brewster, Nat. Rev. Drug Discovery, 2004, 3, 1023.

22 A. Harada, R. Kobayashi, Y. Takashima, A. Hashidzume and H. Yamaguchi, Nat. Chem., 2011, 3, 34.

23 J. W. Chung, Y. Guo, R. D. Priestley and S.-Y. Kwak, Nanoscale, 2011, 3, 1766 .

24 J. Szejtli, J. Mater. Chem., 1997, 7, 575.

25 M. Messner, S. Kurkov, P. Jansook and T. Loftsson, Int. J. Pharm., 2010, 387, 199.

26 M. G. McKee, C. L. Elkins and T. E. Long, Polymer, 2004, 45, 8705.

27 S. Talwar, J. P. Hinestroza, B. Pourdeyhimi and S. A. Khan, Macromolecules, 2008, 41, 4275.

28 Y. Wu and R. Clark, J. Colloid Interface Sci., 2007, 310, 529.

29 M. P. Cashion, X. Li, Y. Geng, M. T. Hunley and T. E. Long, Langmuir, 2010, 26, 678.

30 M. McKee, J. Layman, M. Cashion and T. E. Long, Science, 2006, 311, 353.

31 A. W. Coleman, I. Nicoli, N. Keller and J. P. Dalbiez, J. Inclusion Phenom. Mol. Recognit. Chem., 1992, 13, 139.

32 M. Bonini, S. Rossi, G. Karlsson, M. Almgren, P. Nostro and P. Baglioni, Langmuir, 2006, 22, 1478.

33 A. Celebioglu and T. Uyar, Chem. Commun., 2010, 46, 6903.

34 A. Celebioglu and T. Uyar, Langmuir, 2011, 27, 6218.

35 L. Szente, J. Szejtli and G. Kis, J. Pharm. Sci., 1998, 87, 778.

36 W. Hinze, D. Pharr, Z. Fu and W. Burkert, Anal. Chem., 1989, 61, 422. 